"Hle sufferings from the lost limb were long and panful. A nerve had been taken up in one of the ligatures at the time of the operation and the ligature, according to the practice of the French surgeons, was of silk instead of waxed thread; this produced a constant irritation and discharge and the ends of the ligature being pulled every day in hopes of bringing it away occasioned fresh agony. He had scarcely any intermission of pain, day or night, for three 'months after his return to Ergland. Lady Nelson at his earnest request attended the dressing of his arm till she had acquired sufficient resolution and skill to dress it her self. About the end of November, after a night of sound sleep, he found the arm nearly free from pain. The surgeon was immediately sent for to examine it and the ligature came away with the slightest touch ; from this time it began to heal."

This would appear to be reasonable enough to the lay mind, but it is not so easy for a surgeon to believe that the alleged separation of a ligature from a nerve, which would bave become gangrenous at the point of constriction a few hours after its application four months previously, would be followed by the imm diate relief of pain On such insufficient evidence was the poor surgeon of the Theseus public'y, if not privately, condemned, his career probably blighted, and bis surgery stigmatised as clumsy and awkward by every biographer of Nelson from Clarke and McArthur down to Captain Mahan. Is it not possible to explain Nelson's condition during these four months without blamirg the surgeon for an error which has never been proved against him? Nelson's nervous system was always highly strung and over-sensitive. Two days after he lost his arm he wrote to Sir John Jervis saying that he was become a burden to his friends and useless to his country-" I become dead to the world and am no more seen "-and asking the Admiral for a frigate to convey "the remains of my carcass to Kngland." This extreme mental depression would without doubt intensify the neuralgia of the stump so frequently experienced after amputation and he would also suffer, as Mr. Owen pointed out, from the absorption of small doses of septic discharge from the walls of the sinus which would naturally make him ill and irritable. By the end of August, moreover, the knotted loop of the ligature would be lying loose in the cul-de-sac at the bottom of the sinus imbedded in a mass of granulation tissue, the artery would be well retracted up amongst the muscles, and its lumen obliterated by organised clot up to the collateral circulation. The cut median nerve, on the other hand, being non -retractile, wonld still have its cicatrising, bulbous end in close proximity to the knotted loop which might possibly be a source of irritation to it. Be that as it may, the removal of the ligature would put an end to his ill-health and the bad effects produced by restless chafing against the delay of convalescence. Life wonld become bearable again-any remaining neuralgia of the stump conld be borne with equanimity. "Richard was himself again " and fit for duty, so we find him on Dec $8 \mathrm{~b}$ sending the following form of thank giving to the minister of st. George's, Hanover-square: "An officer desires to return thanks to Almighty God for his perfect recovery from a severe wound and also for the many mercies bestowed on him." On Dec 191 h be was appointed to the command of the Vanguard - I am, Sirs, yours faithfully,

Epworth, Feb. 24th, 1904.

A. F. Mgesiter.

\section{RAYS PROCEEDING FROM ACTIVE MUSCLES AND NERVES.}

\section{To the Editors of THE LANCET.}

SIRS, - With reference to the communication on this subject from Dr Hugh Walsham and Mr. Le lie Miller, which appear - in THE LANCET of Feb. 27th, p. 610, and with refer ence also to your enitorial notes thereon, I should like to be allower to say that during the past few weeks I have spent mu $h$ time in $\epsilon$ ndeavouring to confirm the experiments of M. Blonr lot and also of M Charpentier, and have publisher the resul's of my investigations in the columns of Nature and of the Elertrician. It is hy $\mathrm{n} n$ means difficult to get some of the effects that $M$ Blordlot and $M$ Charpentier and also $701 \mathrm{r}$ correspondents describe, but sc far as my observations go, these effects when obtained, are in every case due simp'y to heat and require no new description of rars for their explanation. The luminosity of calcium sulphide. as also of mo-t other phost hr rercent substances, is considerably affec!ed by minute differences of temperature ; for instance, a coin taken from one's pocket and held at the back of a calcium sulphide screen will, by reason of its warmth, show through the screen as a disc of increased luminosity in a few seconds. Again, if two small screens covered with this material are placed upon two similar bodies, differing in temperature by only $2^{\circ} \mathrm{F}$., it is easy to discover which of the two bodies is the warmer by the superior luminosity of the screen placed upon it. Again, the mere warmth of the breath is quite sufficient materially to increase the brightness of a suitable phos. phorescent screen.

Difference of temperature is, I believe, the explanation of the "foot" experiment described by your correspondents. I have repeated this experiment with entire success and I must confess that at first sight it seems most convincing. My method is to use two very small calcium sulphide screens each about 16 millimetres by two millimetres in size and of normally equal brightness. Both are placed upon the floor and give an equal amount of luminosity; then one is placed on the foot and is found to brighten up con-iderably as compared with the other. Unfortunately, however, for the " $n$ " ray theory I find no necessity for the presence of the foot at all, nor do we require active muscles or nerves to produce the effect. A boot newly taken off and still retaining some warmth, or any other warm object, acts equally well, while if one screen be placed on the foot and the other upon a can of water heated to the same temperature as the foot no difference can be detected between the luminosity of the two screens. Again, the "foot" experiment does not succeed if a good thickness of paper or cardboard is placed between the foot and the screen so as to prevent the transference of warmth to the latter.

I have described my observations with regard to this "foot" experiment at some length as your correspondents describe it as "one of the most convincing tests," but my conclusions are similar-i.e, that the effects are simply due to heat, with regard to other parts of the body. I am quite ready to believe that certain parts of the body and certain muscles and nerves in a state of activity may possibjy be more efficient than others in producing extra luminosity in the screen. I have not been able to observe this myself, but assuming that it is so I would suggest that local differences of temr erature and of heat radiation will account for these effects without having recourse to recondite theories and to new descriptions of rays.

I note that your correspondents think it necessary to give a word of caution as to the effects of heat and state that they have confirmed some of M. Charpentier's experiments whereby he claims to have proved that the effects he has noted are not due to heat only. It would be interesting to learn exactly what these experiments that your correspondents have confirmed actually ure. I have not personally tried M. Oharpentier's "frog " experiment and can therefore give no opinion in regard to it. As mentioned above, however, I bave found, contrary to his observations, that layers of cardboard forming a heat screen do interfere with the - ffect. Again it does not seem to me that M. Charpentier's experiment wherein he raised the screen to a greater temperature than the animal experimented with is in any way conclurive as the proximity of any body, the temperature of which exceeded that of the air. to the screen would obviously trnd to decrease the heat radiation from the latter and might therefore have the $\mathrm{fffect}$ of retaining its ten perature and of increa ing its luminosity in comparizon with another screen not so acted up on.

I should like to add that personally I have been investigating the " $n$ " rays not so much from a physic logical as from a physical standpoint and the greater part of my experiments have so far been directed to arcertain the existence of these rays as given off, according tn M. Blondlot, bv Aurr incanre cent gas mantles and by Nernst electric lamps. So far I have been quite unsuccessful in convincing myself tbat these " $n$ " rays have any real objective existence at all, but without definitely concluding that the effects - bserved are subjective I am quite ready to armit that there may be efftcts visible to some persons to which I myself and my assistants and others who have also obtained negative results are blind. It may, in fact be a matter similar to "colour blindness" orly in another form. In any case, however, I would warn experimenters in this mo-t $n^{+}$eresting field that the :ubject is full of pitfalls. The accurate observation of these dim phoswhoreccent ohjects is really very difficult owing to the fact that diff-, ent parts of the human retina are very unequally sensitive to faint 
lights, while optical fatigue and other phencmena are apt to abscure the results.

I am, Sirs, yours faithfully,

Westminister, S.W., Feb. 29th, 1904.

A. A. OAMPBELL SWINTON.

\section{HUMAN AND PLANT RAYS.}

\section{To the Editors of THE LANCET.}

SIRS,-Having recently been in Paris I had whilst there an opportanity of an interview with Dr. Baraduc who was kind enough to give me a prepared screen by which to demonstrate the " $n$ " rays. The other night Dr. Hugh Walsham and I were experimenting with this screen. We first of all excited it by means of an ultra-violet lamp after which we easily obtained luminosity when it was in contact with any part of the surface of the body, but, as I told Dr. Walsham, its excitation by the lamp was by no means necessary after each test. This was proved by first allowing all prior emanations to pass off, then, when no glimmer of fluorescence was perceptible, we placed the screen on the floor at a distance of three feet from where we stood. All was total darkness, but after placing my finger under the screen for a minute the glow was quite apparent.

To show that these emanations were not due to heat rays, we filled a hollow metal lens (made for the purpose) with very hot water and held the screen quite close to this lens; there was absolutely no brightening, in fact the illumination caused by the previous contact with my temple gradnally dulled down while the screen was still in the path of the caloric rays. I also lodged the screen, after allowing a sufficient interval of time for previous emanations to pass off, amongst the branches of a mimosa plant; the luminosity appeared in a few minutes and in this case apparently could not be due to heat rays. Personally I have known for some years, and have satisfied myself on the point scores of times, that rays (vibrations) are given off from all organic beings and inorganic substances; those emanating from ourselves I have usually designated "human rays." It is common knowledge among all who have dipped into occult matters that these "etheric vibrations" have been demonstrated by Reichenbach 50 or more years ago. "Emanations" from human beings are referred to by learned Indian writers as far back as 2000 B.C. - and before that for all 1 know to the contrary.

I am, Sirs, yours faithfully,

J. STENSON Hooker, M.D. Durh.

Gloucester-place, W., Feb. 22nd, 1904.

\section{THE CAUSES OF HIGH INFANTILE MORTALITY.}

To the Editors of THE LANCET.

Sins, - I cordially welcome your remark ( $p$ 452) that "the children of the poor are a national asset" and ask permission to say a few more words on this subject. Dr. J. M. Rhodes's figures (p. 462) show, what no one doubts-viz., that density of population is a canse of high infantile mortality. They do not show that restriction of medical relief is not also one of the causes ; hospitals and dispensaries will not make up for the medical man's visits and advice at the home. Sometimes the baby is taken back from the hospital to die; it ought not to have been brought out into the cold. Dr. Rhodes's figures as to the counties are not of much use as the counties comprise unions which vary as to relief and also as to density. They do, however, suggest (what, indeed, we know) that ignorance of mothers is one of the causes. I quite agree with Dr. Rhodes that the custom of the mothers of infants working in factories is another cause. In both these cases the advice of the medical adviser would be most useful and, if followed, might save many lives. I think the guardians, also, should, in the case of children for whom they give out-relief, allow milk instead of the usual loaf. And in the case of nursing mothers it might often be well to allow milk for the mothers.

As to my London figures I think a glance down them will show that, though they do not actually prove that restriction of medical relief is one of the causes of infantile mortality, they do make it worth while for a medical officer of health, where high infantile mortality exists, to inquire into the matter:

Let me add a few words from Mr. Charles Booth's final volume on "Life and Labcur of tha People of London." $\mathrm{He}$ gites at p. 17 a valuable list of distribts in order of deathrate; poverby, \&e. He says (p 18):-

In St. George's-in-the-East and Suadwell the death-rate is at it highest, although this district stands only fourth in crowding, sisth in poverty, and eighth in its birth-rate. For this discrepancy there is no very obvious explanation. It is, however, probable that the high death-rate has been connected with the intermittent and exposed character of much riverside labour. ..... Bethnal Green stands about fourth in everything except death-rate. which is as unaccountedly low as that of St. George's-in-the-East is bigh.

It will be seen that the infantile mortality of St. George's. in.the-East is also far above that of Bethnal Green; and I would suggest that the different action of the guardians may possibly account for a part of the difference. I think also. that the death-rate among the non-Jewish portion of the population of Whitechapel requires attention but cannot. venture to take up more space in this letter. I should add that $\mathrm{St}_{\text {t }}$ George's-in-the-East guardians have practically abolished ordinary out-relief but do give some medical relief. Feb. 25th, 1904.

$$
\text { I am, Sirs, yours faithfully, }
$$

J. THEODORE DODD.

\section{THE PROPOSAL TO PROHIBIT MEDICAL PRACTITIONERS FROM DISPENSING.}

\section{To the Editors of THu LaNOET.}

SIRs, - Those who have followed the recent discussion in THE LANCET on dispensirg by medical men will have noted that the question of prohibition bas been treated by its opponents almost exclusively from a commercial point of view. They trouble themselves but little to reflect whether the interests of the medical profession as a whole are better promoted by prescribing or by dispensing, which of the two systems is more just in its relation to the public or which tends more to efficiency in practice. Yet these are considerations of the highest significance which must in the end govern and include the commercial. Let it not be thougbt that I undervalue the latter. I fully admit its importance, bat it is clear that the foundation upon which it rests, the character and quality of work done, is more important still. The reform of a system which entails upon practitioners the discharge of services tedious in themselves and not essential since they are proper to the druggist, cannot but tend to increase their professional usefulness. The assumption that his drugs are superior to those of the chemist is a pure invention, What, after all, do the arguments against the supersession of dispensing amount to? It is asserted that patients will not consent to pay both doctor and chemist, that they will prefer to be treated by the latter, and that they will be "driven" to dispensaries and hospitals. No proof is adduced in support of these assertions. We are asked to accept as virtual certainties what are at best merely suggested probabilities. I have found that in my mixed practice patients do pay both me and the druggist and, as a rule, without demur. I doubt if even in club attendance an adjustment equitable to the members and satistactory to both practitioner and chemist would prove impossible if only medical men were united in trying to bring it about. One of your correspondents, writing with evident knowledge of the subject, assures us that the prescribing chemist is practically non-existent, and it would be difficult to conceive a system better calculated than the present to encourage retaliation by the chemist upon the practitioner. As to dispensaries, the worst offender of them all, the cheap private dispensary, would be suppressed by prohibition and the medical profession generally would rejoice in its overthrow. Hospital abuse is so prevalent already that if dispensing practice is to be considered an antidote to this disease it is surely one of the mildest. It is improbable that any remedy for it will be obtainable until we discover a hospital conscience of reliable strength. The real crux of the difficulty which stands in the way of prescribing, however, is not to be looked for in any of these objections. It consists in the disinclination of many medical men to part with what they regard as their vested interest in a prescription. In other words, the remedies dispensed for or by them are' considered to be proprietary and a patient every time that he has to renew his bottle of physic must be credited with a fresh consultation. This may be a profitable transaction so far as the practitioner is concerned, but I do not think it should be regarded as pro. fessional. Treatment only, not the sale of drugs, is the true function of a medical man. If he requires to supervise his patient's condition he onght to instruct the latter to this 